\title{
¿CÓMO IBAN A TERMINAR LOS AMORÍOS DE DOROTEA Y DON FERNANDO? PRIMERA PARTE DEL QUIJOTE
}

Las cinco narraciones interpoladas en la Primera parte del Quijot e(Madrid, 1605) son las historias de (1) Marcela y Grisóstomo (capítulos 12-14), (2) Dorotea, don Fernando, Luscinda y Cardenio (capítulos 23-32, 35-38, 42-47), (3) Camila, Anselmo y Lotario (capítulos 33-35), (4) Zoraida, el Cautivo, doña Clara y don Luis (capítulos 39-41 y 43-44), y (5) Leandra y Vicente (capítulo 51). Todas estas historias son variaciones de un mismo tema universal, las vicisitudes del amor. La historia de Grisóstomo y Marcela y la de Leandra y Vicente, y lo que Cardenio y Dorotea cuentan en Sierra Morena, son narraciones de amores malogrados. Grisóstomo se queja en sus poemas de amores mal correspondidos y muere de ellos, Cardenio está a punto de perder la razón porque cree que Luscinda se casó con su rival, Dorotea anda en el monte y Leandra está en un convento porque fueron engañadas, seducidas y abandonadas por sus amantes. La conclusión de la historia de Cardenio y Luscinda, la historia del Cautivo y Zoraida, y la de doña Clara y don Luis, por el contrario, son narraciones en las que triunfa el amor.

"El curioso impertinente", la trágica historia de un triángulo amoroso entre Anselmo, su esposa Camila y su mejor amigo Lotario, es única porque no tiene nada que ver con la acción principal de la novela. Tanto el Quijot ecomo la "novelita ejemplar" podrían existir el uno sin la otra, o viceversa, algo a lo que ya hace referencia el bachiller Carrasco en el capítulo 3 de la Segunda parte de la obra (Madrid, 1615): "Una de las tachas que ponen... es que su autor puso en ella una novela intitulada El curioso impertinent : neo por mala ni por mal razonada, sino por no ser de aquel lugar, ni tiene que ver con la historia de su merced del señor don Quijo- 
te"l. Cervantes podía haber interpolado cualquier otra de sus "novelas ejemplares" en lugar de El curioso impertinente, y nadie notaría la diferencia. También se puede inferir de la crítica del bachiller, que las otras cuatro narraciones interpoladas sí son parte integral de la novela.

El pasaje más importante de la historia del estudiante Grisóstomo y la pastora Marcela es el discurso que ésta hace para defenderse de lo que se dice de ella en la comarca. El discurso es un encomio de las leyes naturales (libertad física y libre albedrío) y un ataque contra las convenciones impuestas por la sociedad y, por lo tanto, se pronuncia ante un grupo de pastores y cabreros en el marco de Sierra Morena. Y este mismo plató, u otro semejante, era el que necesitaba Cervantes para que Cardenio, Dorotea y el enamorado de Leandra contaran sus penas de amores. Marcela, Dorotea y Leandra son villanas, y sus historias son, como las de los despechados Cardenio y Eugenio, narraciones de amores infelices. Así pues, ni las jóvenes encajan dentro del círculo social de las damas y caballeros hospedados en la venta, ni sus cuitas con las felices parejas de enamorados que coinciden ahí. Pero para la conclusión de las historias de Cardenio y Dorotea se necesitan otros personajes además de don Quijote, el cura y el barbero: se requiere la presencia de don Fernando y Luscinda.

El cura atribuye el arribo de don Quijote y de todo su grupo a la venta, y la subsiguiente llegada de Luscinda y don Fernando (quien había raptado a Luscinda de un convento y la llevaba de regreso a Andalucía por la fuerza), y la del resto de los personajes que ahí se congregan por dos días, a una "particular providencia del cielo" (p. 453), pero la localización de la venta en un cruce de caminos también ayuda. La venta está idealmente emplazada para que en ella sucedan toda clase de coincidencias y reuniones, tanto tristes como felices, de encuentros y soluciones, tanto imprevistos como arreglados; y es ahí, precisamente, a donde llegan y coinciden el cura, el barbero, don Quijote, Dorotea, Cardenio, don Fernando, Luscinda, el Cautivo, Zoraida, el oidor, doña Clara y don Luis.

La culminación de la historia Dorotea-don Fernando-Luscinda-Cardenio es el discurso de Dorotea en la venta (cap. 36; pp. 450-451 y 453). El carácter ético-moral (honor, deber, jus-

${ }^{1}$ El ingenioso hidalgo don Quijote de la Mancha, ed. L. Andrés Murillo, Clásicos Castalia, Madrid, 1978, t. 2, p. 63. Todas las citas son de esta edición. 
ticia) que subraya el discurso de la labradora requiere un auditorio más selecto que el de cabreros y pastores, necesita oyentes que puedan comprender y apreciar su propósito, y la presencia del bien nacido seductor. ¿Ante qué mejor juez puede apelar Dorotea sobre el sagrado juramento que le hizo don Fernando, que ante el cura? ¿Qué mejor público para apelar a la caballerosidad y al honor de don Fernando, que los amigos de éste? ¿Qué mejor lugar para apelar a los sentimientos de su amante, que en presencia de los dos enamorados que éste trató de separar?

Así pues, los pivotales discursos de Marcela y Dorotea se pronuncian en el lugar apropiado y precisamente frente al tipo de público que requieren. Si las posiciones de estos discursos se invirtieran, la reacción de los oyentes sería totalmente diferente. Los pastores de Sierra Morena habrían culpado a Dorotea de su desgracia sin simpatizar con ella, aceptando la traición de don Fernando como una inconsecuente aventura con una vasalla, su droit de seigneur. El cura, el barbero, don Fernando, Dorotea y la enamorada pareja que forman Cardenio y Luscinda, habrían encontrado el discurso de Marcela discorde, contrario a la naturaleza humana, y por demás absurdo. Y esto explica, creo yo, el que Cervantes haya interpolado el episodio de Grisóstomo y Marcela en Sierra Morena, el de Cardenio, Dorotea, don Fernando y Luscinda en la sierra y en la venta, los del Cautivo y Zoraida y de doña Clara y don Luis en la venta, y el de Leandra y Vicente a campo raso. Cervantes aprovechó dos elementos que ya tenía en su novela, la sierra y la venta, para crear los diferentes montajes y los dos tipos de público que necesitaba para poder interpolar estas historias de amores en la Primera parte del Quijote. Cervantes ya ha de haber tenido estas narraciones escritas, pero es evidente que, dadas las inconsistencias textuales que existen en la novela (la inexplicada desaparición del rucio, los epígrafes equivocados, las dos cenas en una misma noche), las versiones originales de estas historias han de haber sido un tanto diferentes de lo que tenemos ahora. La única novela ejemplar que se menciona en el Quijote es Rinconete y Cortadillo, una narración inconclusa que se publicó así en 1613. Es muy posible, pues, que con la única excepción de El curioso impertinente, todas las otras narraciones interpoladas hayan estado sin terminar cuando Cervantes decidió usarlas a principios de siglo en la Primera parte del Quijote. La historia de Dorotea, don Fernando, Luscinda y Cardenio, por ejemplo, abunda en 
contradicciones internas, lo que sugiere que esta narración aún estaba sin conclusión. Una de las historias del cuadrángulo amoroso parece quedarse en el limbo porque el texto no nos da una contestación definitiva a la pregunta, ¿cómo acaban los amoríos de don Fernando y Dorotea? Pero cuando se lee esta interpolación detenidamente, cuando se comparan entre sí las diferentes situaciones y características de los personajes tejidos en la trama de las narraciones intercaladas, y cuando se comparan éstas con otros episodios del Quijote, la respuesta que surge es inequívoca.

Se menciona a Dorotea y a don Fernando por primera vez en la narración que Cardenio hace de sus propias desventuras. Dorotea, dice Cardenio, era "una labradora, vasalla [del padre de don Fernando] ... tan hermosa, recatada, discreta y honesta, que nadie que la conocía se determinaba en cuál destas cosas tuviese más excelencia ni más se aventajase" (p. 294). Pero los que encuentran a Dorotea en Sierra Morena son, además de Cardenio, el cura y el barbero. La descubren en atuendo de labrador, e inmediatamente "el mozo" les parece no "persona humana, sino divina": sus pies eran "dos pedazos de blanco cristal", tal era "su blancura y belleza"; su pierna "de blanco alabastro parecía"; a sus cabellos "pudieran los del sol tenerles envidia"; los "luengos y rubios cabellos" la cubrían casi totalmente, "tales y tantos eran"; "las manos en los cabellos semejaban pedazos de apretada nieve". Cuando les habla, lo hace "con voz tan suave, que no menos les [admira] su discreción que su hermosura", y cuando le preguntan por qué se queja, "sin hacerse más de rogar, calzándose con toda honestidad... con voz reposada y clara" comienza Dorotea su triste historia (pp. 345-347).

Mis padres son unos muy ricos y honrados labradores, dice Dorotea, que me adoraban y cuidaban como a la niña de sus ojos. Yo era la administradora de toda su hacienda, y en los ratos que me quedaban libres me entretenía en "ejercicios que son a las doncellas tan lícitos como necesarios": cosía, hilaba, leía libros devotos y tocaba el arpa. Rara vez salía de casa, y cuando "iba a misa... [iba] tan cubierta y recatada que apenas vían mis ojos más tierra de aquella donde ponía los pies", pero aun así me vio un día don Fernando, y apenas me hubo visto "cuando, según él dijo después, quedó... preso de mis amores”. Empezó a asediarme con cartas, músicas y ruegos, y "me daba un no sé qué de contento verme tan querida y estimada de un tan principal caballero". Mis padres me aconsejaron que no hiciera caso de sus pro- 
mesas, y me dijeron "que ellos me casarían luego con quien yo más gustase... pues todo se podía esperar de su mucha hacienda y de mi buena fama". Yo nunca le di a entender a don Fernando que había alguna esperanza de que alcanzara sus deseos, pero una malhadada noche, "estando yo en mi aposento... me le hallé delante" de mí. Del susto "me enmudeció la lengua", y no pude pedir socorro, pero después de muchas súplicas, promesas y lloros de su parte, empecé a compadecerme de él. Le dije entonces que si se salía con sus deseos tendría que ser mi legítimo esposo, a lo que don Fernando inmediatamente respondió: "Si no reparas más que en eso, bellísima Dorotea... aquí te doy la mano de serlo tuyo, y sean testigos desta verdad los cielos... y esta imagen de Nuestra Señora”. Con esto, pensé entre mí, "no seré yo la primera que por vía de matrimonio haya subido de humilde a grande estado... [y] bien es acudir a esta honra que la suerte me ofrece". Así que llamé "a mi criada, para que en la tierra acompañase a los testigos del cielo", y don Fernando "añadió a los primeros nuevos santos por testigos... y con esto, y con volverse a salir del aposento mi doncella, yo dejé de serlo" (pp. 348-354). Rindióse Dorotea, Dorotea se rindió.

A pesar de que don Fernando sigue con sus fiestas y cacerías en la comarca, nunca más vuelve a casa de la labradora después de esa noche, y a los pocos días se ausenta de la villa. Un mes después, Dorotea se entera de que don Fernando se acababa de casar con una dama bien nacida, aunque no tan rica como ella, y esa misma noche se viste de labrador, abandona su casa en compañía de un criado de su padre, y se va a la ciudad en busca de su seductor. Dos días y medio después llega a la ciudad, donde descubre lo que había pasado en las bodas de Luscinda y don Fernando, y oye un público pregón en el que se decía que la había sacado de su casa el mozo con el que iba, y se ofrecía una recompensa al que la hallase. Se da cuenta Dorotea entonces, por primera vez, "cuán de caída andaba [su] crédito" (p. 357), pues no sólo era público ya que había abandonado su casa, sino que además se presumía que lo había hecho por amores con un zagal, criado de su padre. En vez de volverse a su familia, Dorotea y su criado se internan por lo espeso de la montaña, a pesar de que ella bien sabe que el mucho amor que sus padres le tienen le asegura que será "dellos bien recebida" (p. 359). Como era de esperar, el zagal pronto pierde el respeto que le tenía a su ama y trata de aprovecharse de ella por la fuerza; ella se defiende y empuja al mozo en un derrumbade- 
ro, donde lo deja sin saber si queda vivo o muerto; se interna más en la sierra; entra a trabajar de mozo con un ganadero, al que abandona cuando se da cuenta que había descubierto que era mujer y antes de que éste intentara violarla; y permanece en el monte por meses hasta que la descubren lavándose los pies, el cura, el barbero y Cardenio.

Después, cuando el cura le explica a la labradora la razón por la cual ellos también andan por la sierra, Dorotea, sin más ni más, se ofrece a ayudarlos y a hacer ella el papel de doncella menesterosa. Procede entonces a ponerse unas joyas y unos vistosos y ricos vestidos que traía consigo, contentando a todos en extremo "su mucha gracia, donaire y hermosura" (p. 362). Van en busca de don Quijote y, cuando lo encuentran, Dorotea inventa una historia según las que ella había leído en los libros de caballerías, y así consiguen sacar al caballero de su penitencia en la sierra y llevárselo sabrosamente engañado camino a su pueblo. Ya en la venta, llegan tras ellos Luscinda y don Fernando para pasar allí la noche. Cardenio y Dorotea reconocen a los recién venidos, y la labradora inmediatamente se arrodilla a los pies de don Fernando y elocuentemente le suplica que cumpla la palabra de casamiento que le dio. Don Fernando, después de muchas súplicas, levanta a Dorotea, la abraza, le dice que cumplirá su palabra, y le pregunta que cómo es que ella se encuentra en la venta, tan lejos de su lugar. Dorotea le cuenta sus peripecias "con breves y discretas razones... [y] con tanta gracia”, que don Fernando y sus compañeros quedan encantados (p. 455). Todo esto hace sospechar a Sancho que Dorotea no es más princesa que su madre y, finalmente, cuando su amo le manda ensillar a Rocinante para continuar la aventura, Sancho le replica delante de todos los huéspedes que, de ser Dorotea lo que ella dice "no se anduviera hocicando con alguno de los que están en la rueda, a vuelta de cabeza y a cada traspuesta" (p. 551). Sancho cree "que aquella desenvoltura más era de dama cortesana" que de reina (p. 552). Dorotea se corre $\mathrm{y}$, muy posiblemente como resultado de la vergüenza que tanto ella como su amante pasan frente a toda la ilustre compañía, abandonan la idea de continuar con don Quijote y su grupo. Cuando el cura y el barbero se despiden de los huéspedes, don Fernando le promete al cura que le escribirá una carta dándole razón de su casamiento (p. 559); y esto es lo último que se nos dice de Dorotea y don Fernando. Pero, ¿qué les ocurrió después de que los huéspedes se separaron en la venta? 
De las cinco historias de amor interpoladas sólo dos tienen una conclusión definitiva (Grisóstomo y Marcela, El curioso impertinente), mientras que una termina con una gran interrogación hacia el futuro (Leandra y Vicente), y no se nos dice si tres parejas (el Cautivo y Zoraida; doña Clara y don Luis; Cardenio y Luscinda) acabaron casándose, pero no hay duda alguna en la mente del lector que tal fue el caso. Cardenio y Luscinda se aman y se han sido fieles contra todo percance y desventura, y lo mismo pasa con el Cautivo y Zoraida, y con don Luis y doña Clara. No hay ningún impedimento de clase, o de ningún otro tipo, para que estas relaciones no terminen ante el altar. El recato, la castidad y pureza indiscutibles de Zoraida, la noble entereza del Cautivo, y el mutuo amor que se tienen, son todos y cada uno firmes cimientos de una relación indestructible. Y lo mismo puede decirse de las cualidades de Luscinda y Cardenio (el cura dice en una ocasión que "sola la muerte [los] podía apartar", p. 453), y de la inocencia de doña Clara y don Luis (el oidor no sólo aprueba el casamiento de su hija con don Luis, sino que lo desea de todo corazón). Todo lo contrario sucede en el caso de Dorotea y don Fernando.

Por principio de cuentas, es imposible aceptar que Dorotea haya podido andar sola y a salvo por la sierra por cinco o seis meses (Cardenio lleva seis meses en ella, y ambos se internaron en la sierra con sólo unos días de diferencia), o que haya podido pasar por mozo labrador a pesar de su belleza excepcional, la blancura de su tez y su larguísimo pelo, o que el sol y la intemperie hayan respetado la fina textura y el blanco alabastrino de su piel intactos, o que su voz aún sea reposada y clara, o que su compostura apenas si muestre trazas de tan grave aflicción. Tampoco se sabe cómo se las arreglaba para alimentarse, según parece, bien y regularmente. Cardenio, por el contrario, se nos muestra al borde de la locura, dando "puñadas y coces" a los pastores y robándoles su comida, "roto el vestido, y el rostro disfigurado y tostado del sol... con una voz desentonada y bronca" (pp. 287 y 290). Otra diferencia entre los dos personajes está en lo que los dos cargan por seis meses entre matorrales y desventura. Cuando Dorotea abandona su casa pone "en una almohada de lienzo un vestido de mujer, y algunas joyas y dineros" (p. 355), así que cuando se ofrece a hacerla de princesa, lo único que tiene que hacer es sacar "de su almohada una saya entera... una mantellina... y de una cajita un collar y otras joyas" (p. 362). Es difícil imaginar a Dorotea cargando 
en una simple funda de almohada estas cosas durante cinco o seis meses entre vericuetos y abrojos, pero no es algo totalmente imposible de concebir. Es más, esta pincelada magistral nos dice mucho del carácter y, por qué no, de la feminidad de Dorotea en contraste con la masculinidad descuidada y despreocupada de Cardenio. Cardenio hacía meses que había abandonado a la buena de Dios su cojín y maleta, con camisas de holanda, otras cosas de lienzo, más de cien escudos de oro, y un librillo de memoria; y cuando don Quijote y Sancho los encuentran, el cojín y la maleta están "medio podridos o podridos del todo", como era de esperar (p. 281). Claro, Cardenio no tiene ningún uso para estas cosas en la sierra en la que se ha emboscado, mientras que Dorotea salió de casa con ropa y joyas, "por lo que podía suceder" (p. 355); y, lo que sucede, es que estos haberes son precisamente las cosas que Dorotea necesita para transformarse en la princesa Micomicona y continuar sus aventura de disfraces y mentiras.

Dorotea no dice que quiera a don Fernando, sino sólo una vez, cuando le está rogando a éste que renuncie a Luscinda y que la tome a ella por esposa. A cambio de Luscinda, dice Dorotea, "puede ser recompensa... la incomparable voluntad que te tengo... [y te será más fácil] reducir tu voluntad a querer a quien te adora, que no encaminar la que te aborrece a que bien te quiera" (p. 450). La verdad, sin embargo, es que Dorotea, ni le tiene voluntad, ni adora a don Fernando. La pastora solamente quiere que el hijo del duque le cumpla su promesa y se case con ella, sin importarle en lo más mínimo lo que ella tenga que sacrificar. "Y si no me quieres por la que soy", implora Dorotea, "quiéreme, a lo menos, y admíteme por tu esclava; que como yo esté en tu poder, me tendré por dichosa y bien afortunada" (p. 451). Desesperación, que no amor, es lo que sus palabras describen al vivo. Dorotea no tiene, claro está, culpa ninguna de lo que don Fernando le hizo (colarse en su aposento sin su consentimiento, decirle que la amaba, jurarle ser su esposo, violarla y abandonarla), pero Dorotea parece culpar de los resultados de todo esto más a sus padres que a don Fernando. Quizá "nace mi poca ventura", dice Dorotea, "de la que no tuvieron [mis padres] en no haber nacido ilustres... [y creo que] de su humildad viene mi desgracia" (p. 348). Dorotea asume que con los dones naturales que le dio el cielo, y con todo lo que ella sabe hacer y sus padres tienen, debería haber nacido ilustre, que ella es labradora, vasalla del padre de don Fer- 
nando y desventurada en amores, en gran parte porque sus padres no son bien nacidos. Es verdad que Luscinda, a quien don Fernando considera su esposa legítima, aún conserva su virtud a pesar de que éste ha estado tratando de consumar su matrimonio por más de cinco meses sin ningún resultado. No hay duda de que Dorotea achacaría la casta firmeza y el recato de la bien nacida Luscinda a que Luscinda está hecha de barro más noble que ella, pero el caso de la ilustre, infiel y desventurada Camila desmiente la noción de que una persona pueda ser mejor que otra sólo por ser bien nacida. Y don Fernando es otro ejemplo de ello.

La duplicidad de don Fernando es evidente desde el principio mismo de la interpolación, como lo es también el hecho de que nunca había amado a Dorotea. Para alcanzar sus deseos "y conquistar la entereza de la labradora", dice Cardenio, don Fernando había determinado mentirle y "darle palabra de ser su esposo; porque de otra manera era procurar lo imposible" (p. 294). Pero tan pronto como don Fernando "gozó a la labradora, se le aplacaron sus deseos y se resfriaron sus ahíncos", y empezó a planear cómo irse de la región "por no ponerlos en ejecución" (p. 295), "temeroso de lo que el duque su padre haría cuando supiese su disparate" (p. 295). Meses después, y sin haberle dado en el ínterin un segundo de sus pensamientos a la labradora, se la encuentra de repente en la venta con un cura a su lado. Ahí, rodeado de sus amigos, de testigos severos y convincentes, y de aquellos que injurió y traicionó, don Fernando no tiene otro remedio que renunciar a Luscinda enfrente de ellos, y aceptar, o aparentar que acepta, las razones de Dorotea. Pero todos los actos de don Fernando claramente indican que ni ama, ni respeta a la labradora, y el conocimiento de que había pasado seis meses sola por los montes entre follones y villanos que habían tratado de forzarla, sólo puede reafirmar aún más estos sentimientos de desamor y falta de respeto. Cuando el cura, el barbero y Cardenio encuentran a Dorotea, ella es la primera en reconocer que ser mujer y moza, y andar sola en la sierra en traje de labrador son "cosas, todas juntas, y cada una por sí, que pueden echar por tierra cualquier honesto crédito" (p. 347). Si don Fernando faltó a su palabra una vez, y esto cuando él y toda la gente de la comarca tenían a Dorotea por "recatada, discreta y honesta", ¿qué le va a impedir ahora volver a abusar de la labradora en el camino de regreso, y abandonarla después a que siga sus aventuras en el monte? A pesar de todo 
lo que don Fernando dice en la venta, todas y cada una de sus acciones no dejan duda alguna en la mente del lector de la poca estima en que tiene a la labradora, y del poco valor que se le puede dar a su palabra de caballero.

Pero supongamos que don Fernando y Dorotea regresan a su tierra juntos. Hay que recordar: (1) que don Fernando nunca habló con los padres de Dorotea a pesar de las cartas, regalos y flores que llegaban a manos de la labradora a todas horas, y de las constantes músicas con que regalaba sus oídos noche y día, (2) que los padres de Dorotea nunca habían visto con buenos ojos lo que estaba sucediendo, y (3) que don Fernando bien sabía que su padre, el duque, se enfadaría con él y se opondría a tal enlace. Dorotea misma le menciona este obstáculo a don Fernando la noche en que éste la desdoncelló: "[Le dije] que considerase el enojo que su padre había de recebir de verle casado con una villana, vasalla suya" (p. 353). No cabe duda alguna de que don Fernando quería poseer a la labradora sexualmente, pero también es obvio que nunca tuvo la menor intención de casarse con ella. Don Fernando ni amaba, ni había nunca amado a la labradora. Aun después de que Dorotea hace su discurso y su amante parece darse por vencido, cuando don Fernando ve a Luscinda en brazos de Cardenio, los celos lo enfurecen y está a punto de lanzarse contra su rival con la espada en la mano; y sólo el hecho de que Dorotea lo abrace por las piernas y le impida moverse previene este ataque. La ambivalencia misma de la respuesta de don Fernando a las súplicas de Dorotea es sumamente reveladora:

Levantáos [que os] tengo en mi alma... y si hasta aquí no he dado muestras de lo que digo, quizá ha sido por orden del cielo, para que viendo yo en vos la fe con que me amáis, os sepa estimar en lo que merecéis... y pues [Luscinda] halló y alcanzó lo que deseaba, y yo he hallado en vos lo que me cumple, viva ella segura y contenta luengos y felices años con su Cardenio; que yo rogaré al cielo que me los deje vivir con mi Dorotea (p. 454).

Deus ex machina, y cae el telón. Pero esta conclusión no es nada satisfactoria en vista de la evidencia textual acumulada a todo lo largo de la narración original y de lo que agregó Cervantes para unirla al Quijote. Es imposible aceptar que el egoísta, violento y empedernido Don Juan cambie de un minuto a otro y se convierta en don Fernando amoroso, noble y genero- 
so. Y si se estudia su respuesta a Dorotea en detalle, es posible ver que hay algunas fallas en ella: "como vos me amáis tanto, quizá os sepa yo estimar en lo que merecéis", dice don Fernando. El vanidoso Don Juan está seguro de que Dorotea lo adora, pero por su parte sólo espera llegar a estimar a la labradora, en lo que merece. "Luscinda ha alcanzado lo que deseaba, y yo simplemente he hallado lo que me cumple, y viva ella segura y contenta luengos y felices años con Cardenio, que yo rogaré poder vivirlos con Dorotea”. Don Fernando no acepta del todo ni está del todo contento con lo que le está pasando; y esto no le augura a la labradora un futuro ni seguro, ni feliz. Es más, mientras que Lotario, Cardenio y el Cautivo tutean a sus amadas y bien nacidas Camila, Luscinda y Zoraida, don Fernando se dirige a Dorotea, a la labradora, a la vasalla de su padre, usando el vos de distanciamiento social, el mismo vos que Dorotea usa para dirigirse al roto, sucio y mal vestido Cardenio la primera vez que éste le habla de tú en Sierra Morena, creyéndolo socialmente inferior a ella (p. 359). Es de notar, también, que cuando el cura decide dejar la venta y continuar su camino a la aldea, Cardenio, considerando impropio que la "esposa" de don Fernando siga haciendo el papel de princesa Micomicona, ofrece que sea Luscinda la que lo asuma, pero aunque don Fernando se lo agradece, le dice sin ningún reparo que Dorotea continuará con la farsa. Otra indicación de cómo piensa don Fernando es que ni él, ni ninguno de los otros personajes, se refiere jamás a la pastora como "doña Dorotea", lo que sí ocurre, por ejemplo, en un pasaje de la Segunda parte del Quijote en referencia a otra joven que también acaba de terminar una peligrosa travesía sola (caps. 63-65). Al final del episodio de don Gregorio y Ana Félix, don Gregorio dice, citado por Cervantes, que él no puede ni quiere "dejar a doña Ana Félix" en Barcelona (p. 540). Estos dos detalles hacen resaltar el hecho de que Dorotea sigue siendo para don Fernando la misma labradora de hace dos días, no la esposa a la que se debe respetar, ni la noble señora hacia la que todos deben mostrar respeto. Y el hecho de que don Fernando haya abusado de la labradora bajo palabra de casamiento, con los cielos, Nuestra Señora, los santos y aun la traidora criada de Dorotea como testigos (es curioso que no haya en la recámara de Dorotea un crucifijo o un rosario sobre cuya cruz pueda don Fernando hacer su juramento), no cambia la situación en lo más mínimo.

Un pasaje del Quijote que nos muestra claramente cómo se 
veía en esa época la violación de una mujer cuya posición social o económica era inferior a la del hombre que abusaba de ella, y nada menos que desde el punto de vista de otro duque, aparece en el capítulo 48 de la Segunda parte. El "hijo de un labrador riquísimo [deshonra a la hija de una dueña]... debajo de la palabra de ser su esposo" (p. 402), y ahora no se la quiere cumplir. La madre de la joven, doña Rodríguez, dueña de la duquesa, le ha hablado de ello al duque, su señor, pidiéndole justicia, pero el duque se niega a interceder por ellas salvaguardando sus propios intereses; así que doña Rodríguez le pide a don Quijote que rete a batalla al burlador y defienda el honor de su hija. Cuando el reto se hace público, el duque no tiene otro remedio que aceptar que haya una batalla entre don Quijote y el hijo del labrador, pero como el padre siempre le "presta dineros, y le sale por fiador de sus trampas" (p. 402), el duque trata de hacer una farsa de toda la situación. Obliga a uno de sus criados, Tosilos, a que ocupe el lugar del burlador y se enfrente a don Quijote en una justa. Pero cuando poco antes de la batalla Tosilos anuncia que él está dispuesto a casarse con la hija de doña Rodríguez, el duque se enfurece, manda encerrar a su criado con una excusa a gusto de don Quijote: le hace "dar cien palos [a Tosilos] por haber contravenido a las ordenanzas que [le] tenía dadas antes de entrar en la batalla, y todo [termina] en que la muchacha" acaba encerrada en un convento (p. 545). El seductor se sale así con la suya, a expensas de una jovencita de dieciséis años que es obligada a pasar el resto de su vida de monja, sin que esta patente injusticia parezca preocupar ni al duque, ni al rico labrador, ni al seductor en lo más mínimo.

Las condiciones son las mismas en el caso de la deshonra y de la delicadísima situación en que se encuentra Dorotea, y si esto es así, ¿qué razones podemos aducir para suponer que el hijo de un duque quiera o tenga que casarse con una labradora con tachas en su honra, por rica que ésta sea? ¿Qué razones podemos aducir para concluir que el padre de don Fernando, otro duque, y nada menos que uno de los grandes de España, no pensara o actuara de la misma manera que el duque de la Segunda parte para proteger sus propios intereses, especialmente cuando lo que está en cuestión en este caso es el honor, el nombre y la reputación de su propia familia? Don Fernando bien sabía de antemano que su padre se iba a enojar "cuando supiese [el] disparate" que había hecho con Dorotea, aun antes de saber que 
ésta había huido de su casa, así que es dudoso que don Fernando o el duque ahora cambiaran de opinión, todo lo contrario. El duque tiene demasiado en la balanza para aceptar que su hijo se case con una villana cuyo nombre anda por la comarca de boca en boca. Don Fernando se excusará diciendo que no tiene por qué cumplirle su palabra a una labradora que se emboscó por seis meses, como aquellas doncellas que andaban "con toda su virginidad a cuestas, de monte en monte y de valle en valle; que si no era que algún follón, [o] algún villano... las forzaba, [se iban tan enteras] a la sepultura como la madre que [las] había parido" (p. 141). Es muy posible, pues, que don Fernando se negara a casarse con la labradora, que el duque lo apoyara, y que el padre de Dorotea aceptara estas decisiones sin chistar y, como doña Rodríguez y el padre de Leandra, metiera a su hija en un convento para taparles la boca a los maldicientes y salvaguardar el honor de su familia.

Fascinante, también, es estudiar y comparar algunas diferencias que existen entre episodios similares. Los discursos de Marcela y Dorotea son semejantes en tres aspectos: la sinceridad con que se presentan, el formalismo clásico de su estructura y el hecho de que no están dirigidos a ninguna persona en particular. Marcela está contestando al ataque del amigo de Grisóstomo, pero habla desde lo alto de una roca, dominándolo todo, y a todos; Dorotea se dirige a don Fernando directamente y se arrodilla ante él, pero en realidad está dirigiendo sus palabras a todos los huéspedes que la escuchan. De ahí el tono retórico de los dos discursos, el mismo tono usado por Dorotea cuando les narra al cura, al barbero y a Cardenio lo que le había dicho a don Fernando la noche que éste la deshonró (pp. 351352). Pero mientras que Marcela no pide ni necesita la simpatía ni la ayuda de los oyentes, ya que está meramente estableciendo su superioridad y defendiendo su independencia no sólo de Grisóstomo, sino también de todos aquellos que la siguen y requieren, Dorotea está, por el contrario, desesperada. Dorotea no sólo necesita sino que está pidiendo la ayuda y simpatía de todos los que están en la venta, sometiéndose y admitiendo de rodillas la superioridad social y moral de la noble compañía que la rodea, aceptando el hecho de que su honor depende de un hombre, de un hombre que está muy por encima de su nivel social, de un hombre que la deshonró, de un hombre que la rechazó, y de un hombre que no está enamorado de ella. 
Las historias y las personalidades de los diferentes personajes femeninos que se nos presentan en la Primera parte del Quijote también divergen en algunos detalles importantísimos. Una característica de Dorotea que no tiene ninguna de las otras jóvenes es su locuacidad. Dorotea tiene "tan suelta lengua" (p. 347) que en todo se inmiscuye, y habla y dice mucho más de lo que debería para tergiversar los hechos. Tanto es así, que a veces mete la pata, se le olvidan las cosas y se crea líos innecesarios (dice que desembarcó en Osuna - que no es puerto de mar-, y se le olvida el nombre ficticio bajo el cual anda de princesa), teniendo el cura que acudir a su rescate (pp. 373 y 375 ). Como le dice la ventera a su hija, otra jovencita de extracción rural que no necesita mucha cuerda para arrancarse a hablar: "Calla niña... [que] no está bien a las doncellas saber ni hablar tanto" (p. 394).

Los padres de Luscinda la obligan a casarse con don Fernando a pesar de que saben que ella está comprometida y enamorada de Cardenio, y es por eso que Luscinda deja su casa y busca refugio en un convento. Un convento es también el lugar en donde se sugiere que se quede Ana Félix hasta que regrese don Gregorio de la corte y puedan casarse (p. 540). Zoraida abandona su hogar y a su padre impulsada por su amor a la Virgen María. Abandona el Islam en compañía del Cautivo para entrar en la Iglesia Católica. Dorotea, por el contrario, abandona a unos padres que la consienten y adoran, y quienes le han dicho que aceptarán y la casarán con el hombre que ella escoja. Dorotea abandona un hogar honesto al que ella considera un encierro que "al de un monesterio pudiera compararse" (p. 349). Y, una vez fuera, si es la vergüenza lo que le impide a Dorotea regresar a casa de sus padres, ¿por qué no dirigir sus pasos a un convento, avisarles donde está y aguardar ahí a que éstos vengan a buscarla? Dorotea hace exactamente lo opuesto a lo que Luscinda y Zoraida hacen. Dorotea abandona un lugar sagrado y seguro para adentrarse mal acompañada en un mundo de traiciones y peligros. Y esto es, no por coincidencia, exactamente lo mismo que hace Leandra cuando roba a su padre y se fuga con Vicente de la Rosa, un soldado que más tiene de cuentero que de valiente.

Conocemos la historia de Leandra a través de uno de sus enamorados, el cabrero Eugenio. Al principio de su narración, Eugenio dice que Leandra era "de tan estremada hermosura, rara discreción, donaire y virtud" que causaba admiración a todos (pp. 590-591). Pero eso era antes de que Leandra se fugara 
con Vicente. Leandra huyó con su amante de su propia voluntad, "se le entregó la misma noche que había faltado" a su casa (p. 594), los dos pasaron más de una noche juntos, y los aldeanos encontraron a Leandra después de tres días "en una cueva de un monte, desnuda en camisa" (p. 593). Así que ahora todo ha cambiado, sus numerosos enamorados y la gente de la aldea ahora la llaman antojadiza, varia, deshonesta, fácil y ligera. Leandra insiste que Vicente no la deshonró, que tan sólo escapó con las joyas y el dinero que ella llevaba, pero solamente su padre parece aceptar esta versión, aunque a regañadientes y después de mucha reiteración de parte de ésta. Al contrario de Marcela, Leandra no parece tener excusa válida para sus acciones y no aparece para defenderse de lo que de ella se dice, así que sólo nos llega su versión de los hechos de tercera boca, y ya con ella en el convento. Debe notarse, sin embargo, que a pesar de todos los nombres que los cabreros le dan a la pastora Marcela (endiablada, melindrosa, cruel, desagradecida, altiva, fiera, dura, basilisco, mármol, ingrata, arrogante, desdeñosa) ninguno toca a su honra. Pero lo que el cabrero Eugenio, los otros enamorados de Leandra y el resto de la gente de la aldea murmuran de ella es por demás perjudicial a su honra; como lo es para la de Dorotea lo que en seis meses se estará diciendo de ella en los corrillos de la villa y entre todos los villanos de la comarca.

La gran diferencia entre las situaciones en que se encuentran Leandra y Dorotea es que una de ellas aún puede salvarse del claustro, mientra que es dudoso que la otra lo pueda hacer. A pesar de que Leandra se fugó con Vicente, hay muchos cabreros y pastores que todavía están enamorados de ella, no hay ninguna diferencia de clase entre ellos y Leandra, y es muy posible que uno de ellos cierre los ojos y los oídos a su desliz, y se la pida a su padre en matrimonio. Sobre todo, porque dígase lo que se diga y piénsese lo que se piense, Leandra se aferra tenazmente a su versión de que Vicente no abusó de ella. Dorotea, por el contrario, no tiene ningún otro enamorado esperándola, su posición social está muy por debajo de la de don Fernando, y no sólo ha confesado su deshonra a los cuatro vientos, sino que la ha exacerbado con sus aventuras en la sierra y su comportamiento en la venta, humillándose y avergonzando en público y delante de sus amigos al que desea que sea su esposo.

Es posible comprender el enojo y la desesperación que movieron a Dorotea a salir en busca de don Fernando cuando supo que éste se había casado con otra, y hasta admirar su coraje y de- 
terminación, pero debería haberse regresado a casa tan pronto como descubrió y confirmó que las malas noticias que corrían por la comarca eran verdad, puesto que sabía que sus padres la recibirían bien y comprenderían que era totalmente inocente de la canallada que su doncella y don Fernando le habían hecho. Hasta la noche en que don Fernando la deshonró, Dorotea había sido honesta y había seguido los consejos de sus padres, pero no tenía ninguna razón para avergonzarse de que éstos fueran labradores. Nadie le dijo a Dorotea que les ocultara, después, lo que le había sucedido con don Fernando, que los abandonara sin decirles palabra, que huyera de su casa llevándose de compañero a un mozo labrador, que saliera de la villa, que se emboscara en la sierra con su mozo, que lo abandonara mal herido o muerto, que se pusiera a riesgo trabajando para un ganadero, que se pasara meses saltando de monte en monte, que se convirtiera en la princesa Micomicona, que se humillara en público y avergonzara al escurridizo don Fernando delante de sus amigos, que anduviera en la venta besuqueándose con su amante a hurtadillas. Es verdad que Cervantes suaviza la acusación de Sancho diciéndonos que Dorotea se había andado besando con su "esposo", pero basta recordar que a pesar de que tanto Luscinda y don Fernando como Camacho y Quiteria (Segunda parte, caps. 20-21) eran ya considerados "esposos", ninguno de ellos acabó casándose con el otro. Es más, si eso era lo que pensaba Sancho, ¿qué no pensarían de Dorotea las damas y caballeros aposentados en la venta? Nos podemos dar una idea de los pensamientos que cruzarían su mente con lo que nos dice Cervantes de otra pareja de enamorados. Cuando don Gregorio regresa rescatado de Argel, Ana Félix sale a recibirlo "con honestidad... [pero no se abrazan], porque donde hay mucho amor no suele haber demasiada desenvoltura"; siendo sólo sus ojos las lenguas que descubren "sus alegres y honestos pensamientos" (p. 539); y, esto, a pesar de todos los riesgos que Ana Félix había corrido mientras estaba en Argel y en compañía de los corsarios con los que regresa a España.

Es obvio que aunque el carácter de los personajes femeninos parece coincidir en algunos detalles, todas las jóvenes son únicas. Tan pronto como se examinan detenidamente las acciones de Dorotea, comparándolas con las de las otras doncellas y lo que se dice o, quizá más importante, lo que no se dice de ella, en oposición a lo que ella misma dice de sí, se ve que en realidad el único parecido entre Dorotea, Marcela y Ana Félix, 
y entre Dorotea y las damas que están en la venta, es la juventud y la gran belleza física de todas ellas. Los únicos personajes que se pueden considerar paralelos a Dorotea son Leandra y la hija de doña Rodríguez. Las tres jóvenes pierden su honra bajo promesa de matrimonio, Dorotea y Leandra abandonan su hogar y a su familia yéndose con joyas y dinero tras una visión, y dos de ellas, Leandra y la hija de doña Rodríguez, y muy posiblemente Dorotea también, acaban enclaustradas.

Entre los tres infames seductores, no hay ni de dónde escoger. El carácter de los tres es muy parecido. Don Fernando se ausenta después de haber violado a Dorotea para evitar la furia del duque, y trata de casarse con Luscinda para no tener que darle ninguna reparación a la labradora; Vicente simplemente desaparece llevándose las joyas de Leandra; y el burlador de la hija de doña Rodríguez se esconde tras las talegas de plata de su padre. A ninguno de los tres les importa un bledo lo que les pasará a las tres jóvenes que tuvieron la desgracia de confiar en ellos y aceptar su palabra de matrimonio.

La gente de la aldea y los pastores y cabreros enamorados de Leandra que conocen "su discreción y mucho entendimiento no [atribuyen] a ignorancia su pecado, sino a su desenvoltura... [y ahora la llaman] antojadiza, varia... deshonesta... fácil, ligera" (pp. 594-595). No "hay candados, guardas ni cerraduras que mejor guarden a una doncella que las del recato propio", dice el cabrero Eugenio (pp. 591); y esto es, precisamente, lo que don Antonio y sus amigos admiran de la morisca Ana Félix, y lo que los pastores y cabreros de Sierra Morena admiran de una pastora que se pasa la vida entre montes y valles, entre follones y villanos, libre e intocada. La "mesma envidia ni debe ni puede ponerle falta alguna" a Marcela (p. 185), dicen los que la conocen, porque "no ha dado indicio, ni por semejas, que venga en menoscabo de su honestidad y recato" (pp. 165-166). En contra de lo que las constantes alusiones y desmedidas alabanzas de la belleza y perfección física de los personajes femeninos del Quijote sugieren a nuestros sentidos, la conclusión que se saca del texto es muy diferente. Se sugiere, en efecto, que la belleza exterior no es siempre un reflejo fiel del interior humano. La mujer puede ser hermosa, discreta (lista) y deshonesta a la vez. En la España de finales del siglo Xvi y principios del XVII, las cualidades más preciadas en la mujer, fuera ésta mora, morisca o cristiana, sugiere el contexto total, no eran la nobleza de la cuna en que se nacía (recuérdese que Camila también acaba 
en un convento), ni la honestidad impuesta desde fuera por la familia o por la sociedad, ni la belleza física, ni una clara voz, ni el habla fácil, ni la discreción, ni el vestido, ni la riqueza, ni el talento, ni el donaire, ni la gracia; sino la propia honestidad, la virtud y el recato interiores.

La evidencia textual no deja duda a este respecto tampoco. Cuando Dorotea se está preparando a narrar su historia en Sierra Morena, Cervantes nota que la moza se calza "con toda honestidad" (p. 347); pero, sólo unas páginas después, cuando ya conocemos su historia, Cervantes cambia de tono y nos dice que Dorotea se apea "con grande desenvoltura" de la mula en que va montada (p. 364). Cardenio llama a Dorotea "honesta" de oídas, cuando le está contando su propia historia a don Quijote, es decir, antes de conocerla, pero después de oír su historia, y después de que ella misma reconoce que sus acciones habrán "dado materia para que de ella se hable y murmure en la suya y en las ajenas tierras" (p. 358), Cardenio se ha de haber hecho cruces sobre si esta Dorotea era la misma doncella que él había descrito como "recatada, discreta y honesta" a don Quijote (p. 259). Una vez que Cardenio encuentra a Dorotea sola y en la sierra, y una vez que oye sus peripecias, nunca más la vuelve a llamar honesta. De ahí en adelante, los otros personajes y Cervantes continúan llamándola fermosa, hermosa, agraciada, comedida y discreta (p. 462), dicen que tiene mucha belleza, gracia, donaire y hermosura (p. 362), y se admiran de su discreción, hermosura (p. 452) y humildad (p. 454), pero nadie vuelve a llamarla honesta, virtuosa, casta o recatada jamás. Ya en la venta, ninguno de los otros personajes defiende abierta o directamente a la labradora en presencia de don Fernando, con excepción del cura, cuyo principal interés es el de que don Fernando cumpla su juramento y se pruebe caballero y, sobre todo, buen cristiano. Todos la compadecen y tratan de suavizar a don Fernando en masse, pero no hay en el texto ninguna referencia a la honestidad o recato de Dorotea. Y cuando el cura habla, inclusive él mismo lo hace con fórmulas generales. Le recuerda a don Fernando, por ejemplo, "que es prerrogativa de la hermosura, aunque esté en sujeto humilde, como se acompañe con la honestidad, poder levantarse e igualarse a cualquier alteza”, pero se guarda bien de atestiguar que Dorotea sea honesta (p. 454). La velada advertencia del cura, "como se acompañe con la honestidad", es clara indicación de que él no quiere salir por fiador de algo de lo que él mismo no está seguro. 
De todo esto se puede deducir que una de las razones por las que el cuadrángulo amoroso formado por Dorotea, don Fernando, Luscinda y Cardenio se intercaló en el Quijote, fue porque la versión original de la novelita, o no tenía un final, o la conclusión que requería no le había parecido del todo satisfactoria o adecuada a Cervantes. Después de todo, un soldado y el hijo de un labrador rico pueden ser traidores, falsos y disolutos, pero, ¿el hijo de uno de los grandes de España? ¿Cómo publicar que no todos los que tienen sangre noble lo son, y que, como don Fernando, algunos de ellos son unos canallas? ¿Cómo desengañar a Dorotea de la alta opinión que tiene de los bien nacidos y de sí misma, cómo explicarle que debería estar orgullosa de su nivel social y de sus padres aunque éstos no hayan nacido ilustres, cómo decirle que no debería haber aspirado a más de lo mucho que ya era y tenía?

La difícil e incierta situación en que se encuentra Dorotea al final de la interpolación es resultado no de causas exteriores, sino de su propio carácter, o falta de él, de la importancia que le da al hecho de nacer ilustre, de su imaginación y de su vanidad al creer que entregándose a don Fernando subiría "de humilde a grande estado". La labradora perdió su honra en gran parte por la traición de una criada y la canallada de don Fernando, pero a nadie sino a ella se le puede echar la culpa de lo que ocurrió después. Tan pronto como abandonó su casa y los vigilantes cuidados de sus honrados padres, las acciones de Dorotea le hicieron perder toda la buena fama y el buen nombre que tenía, y todo el recato que se le atribuía en la comarca.

El elemento estructual que une a las cuatro narraciones interpoladas, la razón por la que el bachiller Carrasco y los lectores del Quijote las leen como parte integral de la novela, es que las cuatro historias necesitan un auditorio del cual formar parte y hacia el cual abrirse. La historia del Cautivo, Zoraida, doña Clara y don Luis es la doble historia de amores logrados y felices entre miembros de una misma clase social, ni villanos, ni nobles; y en una de las parejas se unen dos razas bajo "la verdadera fe". La venta y los ilustres huéspedes son el local y el público apropiado para que estas historias se desenvuelvan. Otras dos historias (Grisóstomo y Marcela, Leandra y Vicente) se narran y ocurren fuera de la venta porque son historias de amores malogrados entre cabreros y pastoras. Las quejas del estudiante Grisóstomo hubieran sido bien recibidas en la venta, que no la airada defensa de Marcela. El principio de las historias de Do- 
rotea y de Cardenio ocurre y es narrado en la sierra porque trata de abandonos y traiciones, y porque Dorotea es una labradora; pero la conclusión tiene lugar en la venta porque Cardenio, Luscinda y don Fernando son bien nacidos, y porque ambas parejas acaban aparentemente unidas.

Las semejanzas y divergencias en el carácter de los diferentes personajes que conviven en el Quijote demuestran que el elemento estilístico que une las diferentes interpolaciones entre sí, y a éstas con el resto de la narración, es una sutil y bien tejida red de caracterización que las entrecruza, un desenvolver creativo que se centra en la sierra y en la venta, y cuyas espiras nacen, se inspiran y se hacen eco una de la otra sin repetirse jamás. El zurcido casi invisible que Cervantes hizo para unir estas narraciones a la trama principal, y el hecho de que las características internas de cada interpolación coincidan con las de las secciones donde se intercalaron, hacen que las historias se integren con éxito a la novela. Esto no sucede con El curioso impertinente. La ilustre cuna de los protagonistas requiere la venta como escenario y fulcro, pero el trágico carácter inherente en todo triángulo amoroso pide que la historia se narre en la sierra, lejos de las felices parejas que ahí se hospedan. Los fatales resultados de la liaison necesitan tierra non sancta donde Anselmo pueda encontrar, como Grisóstomo, refugio final de sus amores fracasados. Pero Anselmo, Camila y Lotario no son pastores, así que la historia no puede ser narrada ni en la sierra ni entre labradoras y cabreros. Y es por estas razones que la novelita da la sensación de no pertenecer al Quijote. Las otras cuatro interpolaciones, por el contrario, llenan las condiciones estructurales esenciales; y es por eso que Marcela y Dorotea pueden presentar y defender sus acciones en la corte, y ante los jueces más apropiados para cada caso. Es también, por eso, que las otras parejas logran reunirse en la venta y alcanzar ahí la anhelada solución a sus amores.

Es más, al dejar que todas las parejas que estaban en la venta continuaran su camino en aparente armonía, Cervantes se evitó tener que condonar en el altar las cuestionables acciones de Dorotea, o tener que condenarla de por vida a un convento simplemente por su vanidad y su falta de discreción y sentido común. Se evitó, también, tener que condonar una alianza matrimonial entre dos clases totalmente dispares, o tener que condenar la conducta de un hombre cuyo "valeroso pecho... [estaba] alimentado con ilustre sangre" (p. 454), quien a todas 
vistas había jurado en vano y quien, casi seguro, iba a faltar de nuevo a su palabra de caballero, abusando otra vez de la labradora y abandonándola después a su suerte. Interpolando este cuadrángulo amoroso en la Primera parte del Quijote, Cervantes puso al servicio de su historia montajes que ya tenía en pie y los dos tipos de auditorio que necesitaba para su narración, pudo enfocar más el cuestionable carácter de Dorotea, y se evitó tener que plasmar en su manuscrito un final inevitable con el cual no ha de haber estado del todo satisfecho.

R. M. FlORES The University of British Columbia 